\title{
A retrospective analysis of noise-induced hearing loss in the Dutch construction industry
}

\author{
M. C. J. Leensen • J. C. van Duivenbooden • \\ W. A. Dreschler
}

Received: 19 May 2010/Accepted: 15 December 2010/Published online: 4 January 2011

(C) The Author(s) 2010. This article is published with open access at Springerlink.com

\begin{abstract}
Purpose Noise exposure is an important and highly prevalent occupational hazard in the construction industry. This study examines hearing threshold levels of a large population of Dutch construction workers and compares their hearing thresholds to those predicted by ISO-1999.

Methods In this retrospective study, medical records of periodic occupational health examinations of 29,644 construction workers are analysed. Pure-tone audiometric thresholds of noise-exposed workers are compared to a non-exposed control group and to ISO-1999 predictions. Regression analyses are conducted to explore the relationship between hearing loss and noise intensity, noise exposure time and the use of hearing protection.

Results Noise-exposed workers had greater hearing losses compared to their non-noise-exposed colleagues and to the reference population reported in ISO-1999. Noise exposure explained only a small proportion of hearing loss. When the daily noise exposure level rose from $80 \mathrm{~dB}(\mathrm{~A})$ towards $96 \mathrm{~dB}(\mathrm{~A})$, only a minor increase in hearing loss is shown. The relation of exposure time and hearing loss found was similar to ISO-1999 predictions when looking at durations of 10 years or more. For the first decade, the
\end{abstract}

M. C. J. Leensen ( $\square)$

Clinical and Experimental Audiology, ENT Department, Academic Medical Centre (AMC), Room D2-211, P.O. Box 22660, 1100 DD Amsterdam, The Netherlands e-mail: m.c.leensen@amc.nl

J. C. van Duivenbooden

Arbouw, Department of Research and Development, P.O. Box 213, 3840 AE Harderwijk, The Netherlands

W. A. Dreschler

Clinical and Experimental Audiology, ENT Department, Academic Medical Centre (AMC), Amsterdam, The Netherlands population medians show poorer hearing than predicted by ISO-1999.

Discussion Duration of noise exposure was a better predictor than noise exposure levels, probably because of the limitations in noise exposure estimations. In this population, noise-induced hearing loss was already present at the beginning of employment and increased at the same rate as is predicted for longer exposure durations.

Keywords Noise-induced hearing loss - Occupational noise exposure $\cdot$ Pure-tone audiometry $\cdot$ Ear protective devices $\cdot$ Retrospective studies

\section{Introduction}

Noise is an important occupational health hazard, with a high prevalence in the construction industry. The noise exposure of construction workers varies greatly with the activities performed and the equipment used on the worksite (Hong 2005), frequently exceeding daily noise exposure levels of $80 \mathrm{~dB}(\mathrm{~A})$, which the European Directive 2003/10/EC defines as lower action level. This directive also considers an upper action level of $85 \mathrm{~dB}(\mathrm{~A})$, at which the use of hearing protection is mandatory, and an exposure limit of $87 \mathrm{~dB}(\mathrm{~A})$ that takes the attenuation of individual hearing protectors into account.

Long-term exposure to daily noise levels above the lower action level of $80 \mathrm{~dB}(\mathrm{~A})$ may eventually cause noise-induced hearing loss (NIHL), a bilateral sensorineural hearing impairment. Typically, the first sign of NIHL is a notching of the audiogram at 3,4 or $6 \mathrm{kHz}$, with a recovery at $8 \mathrm{kHz}$ (May 2000). This audiometric notch deepens and gradually develops towards the lower frequencies when noise exposure continues (Rösler 1994). 
As a result of the high noise exposures in construction, NIHL is one of the major occupational health problems in this industry. It may have a great impact on a workers' quality of life (May 2000), and it also influences workers' communication and safety (Suter 2002). NIHL is the most reported occupational disease in the Dutch construction sector, with a prevalence of $15.1 \%$ in 2008 (NCvB 2009). In other countries, NIHL is one of most prevalent occupational diseases among construction workers as well (Arndt et al. 1996; Hessel 2000; Hong 2005) and prevalence estimations range from $10 \%$ in the USA (Dobie 2008) to $37 \%$ in Australia (Kurmis and Apps 2007). A large US analysis of self-reported hearing impairment in industrial sectors showed that the largest number of employees with hearing difficulty attributable to employment was found in the construction industry (Tak and Calvert 2008).

Previous studies showed a dose-response relationship of exposure to noise and hearing loss. Higher exposure levels and longer exposure durations cause greater hearing impairment (Rösler 1994; Prince 2002; Rabinowitz et al. 2007; Dobie 2007). This relationship is mathematically described in the international standard ISO-1999 (ISO 1990), predicting both the distribution of the expected noise-induced threshold worsening in populations exposed to continuous noise, and the total hearing levels resulting from NIHL in combination with age-related hearing loss. Hence, the standard also incorporates a database for hearing thresholds as a function of age, for male and female populations separately. This algorithm, indicated as database A, is an internationally well-accepted reference, derived from data of an otologically screened non-noiseexposed population.

The expected noise-induced threshold change is a function of noise exposure level and exposure time. Characteristically, NIHL develops progressively in the first 10-15 years of noise exposure, followed by a slowing rate of growth with additional exposure to noise (Taylor et al. 1965; ISO 1990; Rösler 1994). This pattern is represented in the ISO-1999 model. However, these predictions are based on data from subjects exposed for 10 years or more. The algorithm to predict hearing damage in the first 10 years is interpolated from the predicted median NIHL after 10 years of exposure and the assumed hearing threshold of $0 \mathrm{~dB} \mathrm{HL}$ at the beginning of exposure (ISO 1990), resulting in a steep linear increase in hearing loss during the first years of exposure.

A study of NIHL in railway workers showed that $20 \%$ of final hearing loss at 2 and $4 \mathrm{kHz}$ was already established after the first year of noise exposure. This highly exceeded the predictions of the ISO model, yet after 3-4 years of exposure data and model are in close agreement (Henderson and Saunders 1998). On the contrary, another study found only a slight increase in hearing threshold levels (HTLs) of construction apprentices after the first 3 years of employment in construction industry (Seixas et al. 2005), which was much smaller than predicted by ISO-1999.

Because NIHL is preventable, hearing conservation programmes are established, often relying on employee's use of hearing protection devices (HPDs) rather than on controlling the noise exposure at its source (Neitzel and Seixas 2005). Protection from HPDs depends largely on the consistency of usage, because noise exposure during nonuse greatly reduces their effectiveness (Neitzel and Seixas 2005). Discomfort, hinder to communication and highly variable noise levels, which are common in construction, can cause irregular use of HPDs (Suter 2002; Neitzel and Seixas 2005). Several studies focusing on the use of hearing protectors in construction demonstrated low level of HPD usage; Lusk et al. (1998) found that workers in different construction trades reported to wear protection during only $18-49 \%$ of the time exposed to self-reported high noise. In a more recent study, this percentage was $41 \%$ (Edelson et al. 2009). Neitzel and Seixas (2005) reported an even lower percentage of usage of less than $25 \%$ of the time that combined with the amount of attenuation resulted in negligible effective protection (Neitzel and Seixas 2005). Nevertheless, a study examining hearing loss in Canadian construction workers showed that HPD usage was common $(>90 \%)$ and resulted in a protective effect on hearing (Hessel 2000).

These different findings underline the complicating effects of the consistency of HPD usage in assessing the relationship between occupational noise exposure and NIHL.

In addition, there is also a great variability in individual susceptibility to hearing loss (Henderson et al. 1993; Sliwinska-Kowalska et al. 2006), partly explained by other possible causes of hearing loss. These are both intrinsic and external factors (Sliwinska-Kowalska et al. 2006; Prince et al. 2003). Intrinsic factors are for example gender, race, genetics, medical history and hypertension (De Moraes Marchiori et al. 2006). External factors concern ototoxicity, leisure noise exposure, HPD usage and smoking (Mizoue et al. 2003; Wild et al. 2005).

In this study, a large audiometric dataset of 29,216 construction workers is used to describe their hearing status. The effect of noise exposure on hearing is observed by comparing hearing threshold levels of noise-exposed workers to thresholds of references. The relationship between hearing and noise intensity and noise exposure time is examined, with particular interest in the hearing loss established during the first 10 years of noise exposure. The measured relationships are compared to ISO-1999 predictions. In addition, the influence of wearing hearing protection and other factors collected in periodic occupational health surveys on NIHL is considered. 


\section{Methods}

This cross-sectional study is based on data collected by Arbouw, the Dutch national institute on occupational health and safety in the construction industry. These data are derived from medical records of periodic occupational health examinations (POHE), performed between 1 November 2005 and 20 July 2006 throughout The Netherlands.

A POHE consists of an extensive self-administered questionnaire and a physical examination, including standardized audiometric testing. POHEs are provided for all employees in the construction industry, irrespective of occupational noise exposure. The right to participate is laid down in the collective labour agreement, and participation is completely voluntary.

Demographic, occupational and health-related data are extracted anonymously from the medical records. This includes information regarding job title, use of HPDs (yes/ no), self-reported hearing complaints, noise disturbance at work and the number of years employed in both the construction industry and the current occupation. Cigarette smoking status (non-/ex-/current smoker) alcohol intake $(\mathrm{gl} / \mathrm{wk})$ and blood pressure are also recorded. Hypertension is defined as systolic blood pressure $\geq 140 \mathrm{mmHg}$ combined with diastolic blood pressure $\geq 90 \mathrm{mmHg}$ (De Moraes Marchiori 2006). Independent ethical approval is not needed for this type of retrospective analyses in the Netherlands.

\section{Participants}

The eligible study population contains all 29,216 construction workers who had undergone a POHE in the given period. Hearing threshold levels of the noise-exposed construction workers are compared to different reference groups, in order to separate the effects of occupational noise from those due to ageing and other non-occupational causes of hearing loss. The ISO-1999 standard provides two reference databases: database A, based on a highly screened non-noise-exposed population free from otologic disease, which is used in this study to correct for median age-related hearing loss; and annex $\mathrm{B}$, an alternative database representing a typical otologically unscreened population of an industrialized country, not occupationally exposed to noise. This database derived from representative population-based samples can serve as an appropriate comparison group (Dobie 2006).

The participants of the study population currently exposed to daily noise exposure levels below $80 \mathrm{~dB}(\mathrm{~A})$, such as office workers, can be considered as a comparison group as well. These non-noise-exposed employees are recruited from the same companies and are examined in the same period and according to the same protocol as the exposed subjects.

However, almost two-third of these currently unexposed workers $(65.8 \%)$ reported prior employment in the construction industry. Their past job titles, and corresponding exposure history, are unknown, but past occupational noise exposure cannot be excluded for each of these workers. Since an unscreened industrialized population should not be occupationally exposed, only the 1.016 non-exposed employees without prior employment are considered as an appropriate control group.

These controls show hearing threshold levels (HTLs) very similar to ISO database $\mathrm{B}$, especially in the high frequency region $(3-6 \mathrm{kHz})$. Since these non-exposed employees match the workers under consideration, they form an ideal comparison group (Prince 2002; Prince et al. 2003). Thus, this internal comparison group is preferred over the unscreened ISO annex B to be used as control group in this study.

\section{Audiometric measurement}

Hearing ability is assessed by a qualified medical assistant using standardized audiometric examination procedures according to ISO-6189 (ISO 1983). Pure-tone audiometry is conducted at the workplaces in a mobile unit equipped with a soundproof booth, using a manual audiometer (Madsen Electronics, Taastrup, Denmark) coupled with TDH-39 headphones. Audiometers are annually calibrated according to the ISO-389 standard (ISO 1991). Testing is done during the work shift, but subjects had at least a noise-free period of approximately $2-3 \mathrm{~h}$ prior to testing. Pure-tone air-conduction thresholds are determined at frequencies $0.5,1,2,3,4,6$ and $8 \mathrm{kHz}$ in both ears, in 5-dB increments.

A hearing threshold level of $90 \mathrm{~dB}$ is the upper limit of the equipment and hearing threshold is marked as $95 \mathrm{~dB}$ if the participant does not respond to this maximum sound signal. Because of this ceiling effect, only HTLs up to $90 \mathrm{~dB} \mathrm{HL}$ or better are preserved in this analysis.

Noise exposure estimation

Years of exposure is defined as the years employed in construction industry, as is reported in the questionnaire. If the number of years employed in construction sector exceeds the number of years in the current job, it is assumed that the former job had equivalent exposure levels.

Sound levels are expected to vary more from day to day for the individual workers than between different workers in the same trade. Therefore, workers are classified by the 
time weighted average (TWA) noise exposure levels estimated for standardized job titles.

These daily noise exposure levels were extracted from a database of Arbouw. Most of the estimates reported in this database are retrieved from findings of Passchier-Vermeer et al. (1991). Their findings were based upon a collection of audiometric hearing thresholds of a large population of construction workers. For each profession, the noise levels were derived from the observed HTLs, using a maximumlikelihood fitting procedure in conjunction with the algorithm given in ISO-1999. A comparable approach is used more recently in a military population (Tufts et al. 2009). This way, hearing thresholds can be predicted for populations, even when noise exposure levels are not precisely known. The calculated noise level estimates are a result of all unknown aspects that may have influenced the workers' noise exposure, such as HPD use, non-occupational noise exposure, individual susceptibility and other factors. Therefore, these predictions were verified by noise measurements in 1983, 1991, 2002 and 2007. These measurements are generated by Arbouw and include full-shift personal dosimetry and sound level measurements during specified job-related tasks. Sound level measurements are combined logarithmically in order to calculate an 8-h equivalent noise level, using the duration and frequency of each task. The daily noise exposure levels obtained by dosimetry are arithmetically averaged to obtain job-specific exposure estimations. Table 1 provides an overview of the available data on noise exposure estimates for the twenty most prevalent jobs in the current dataset.

The results of the noise measurements showed good agreement with the noise level calculations for the majority of job titles (Table 1). In case of a deviation, the result of the noise measurements was considered the appropriate noise exposure level to be used in this study. Also, the different measurements performed in different periods showed great similarity.

\section{Exclusion criteria}

Of the 29,216 participants included in this study, all 951 female workers are discarded because of their concentration in non-noise-exposed jobs. Furthermore, one subject lacks all audiometric data and 173 participants show HTLs of $95 \mathrm{~dB}$ HL at one or more frequencies in both ears.

In addition, 357 subjects show HTLs of $95 \mathrm{~dB}$ in one ear and hearing threshold levels of $90 \mathrm{~dB} \mathrm{HL}$ or better at all frequencies in the other ear. For these subjects, only the latter ear is preserved in the dataset.

Data are excluded for 447 workers with insufficient noise exposure data; they miss either information on job title $(n=19)$ or duration of employment $(n=428)$. Finally, the 1,958 currently exposed workers that reported prior employment in construction are excluded from the internal control group.

The excluded participants do not differ significantly from the included subjects, except for younger age $(-3.3 \pm 0.5$ years $)$ and shorter employment duration $(-6.0 \pm 2.9$ years $)$. However, age-corrected hearing loss is similar in both groups $(p=0.908)$.

The study population thus comprises 27,644 men and 54,931 ears.

Data analysis

All statistical analyses are performed using SPSS for windows software, version 15.0. Binaural average thresholds are computed for each test frequency and for all subjects. If threshold levels of only one ear are available, these are regarded as the binaural thresholds and are used for further analyses.

Audiogram data usually have a positively skewed distribution. However, the tested sample is assumed to be large enough to approach a normal distribution and parametric tests are used (Dawson-Saunders and Trapp 1994). The mean binaural hearing threshold levels of exposed workers are compared to age-matched. ISO-standard values using a paired Student's $t$ test, and to HTLs of the nonexposed control group using an independent Student's $t$ test.

In order to compare hearing thresholds of the noiseexposed workers to those of controls and to NIHL predictions by ISO, HTLs of each participant are corrected for age effects by subtraction of the age-matched median HTL predicted by annex A of ISO-1999.

This ISO model assumes that noise-induced permanent threshold shift (NIPTS) and age-related hearing loss (ARHL) are additive, according to the following empirical formula:

$\mathrm{HTL}=\mathrm{ARHL}+\mathrm{NIPTS}-(\mathrm{ARHL} * \mathrm{NIPTS}) / 120$

The correction term (ARHL * NIPTS)/120 starts to modify the result significantly when NIPTS + ARHL is more than approximately $40 \mathrm{~dB}$ HL. To avoid underestimation of NIPTS in this study, this correction term was taken into account in calculating the age-corrected thresholds for measured HTLs exceeding $40 \mathrm{~dB}$ HL.

To simplify the results, hearing loss is also evaluated using pure-tone averages calculated for 1,2 and $4 \mathrm{kHz}$ $\left(\mathrm{PTA}_{1,2,4}\right)$ and for the noise-sensitive frequencies 3, 4 and $6 \mathrm{kHz}\left(\mathrm{PTA}_{3,4,6}\right)$. These parameters are used in multiple linear regression analyses, to investigate the dependence of hearing threshold levels on noise intensity and exposure time. Since there is an important dependence between age and hearing loss, age is also considered as an explanatory 
Table 1 Noise exposure level estimates for the 20 most prevalent job titles, deriving from calculations and different noise measurements

Noise exposure levels are expressed as equivalent 8-h, A-weighted sound-pressure levels $\left(\mathrm{L}_{\mathrm{A}, \mathrm{eq}(8 \mathrm{~h})}\right)$, calculated using an exchange rate of $3 \mathrm{~dB}$

\begin{tabular}{|c|c|c|c|c|c|c|}
\hline & Job title & $n$ & Calculations & $\begin{array}{l}\text { Sound level } \\
\text { measurement }\end{array}$ & Dosimetry & $\begin{array}{l}\text { Intensity } \\
\text { used }\end{array}$ \\
\hline 1 & Carpenter & 10,225 & 91 & & $84-95$ & 91 \\
\hline 2 & Bricklayer & 2,394 & 91 & $87-92$ & & 91 \\
\hline 3 & Painter & 2,082 & 88 & $80-90$ & & 88 \\
\hline 4 & Contractor & 1,748 & 88 & $84-89$ & & 88 \\
\hline 5 & Hodman & 635 & 90 & $80-90$ & & 87 \\
\hline 6 & Engineer (civil) & 582 & 92 & & $81-99$ & 88 \\
\hline 7 & Navvy & 518 & 91 & $81-95$ & & 91 \\
\hline 8 & Paver & 508 & 91 & $86-93$ & & 92 \\
\hline 9 & Plasterer & 412 & 90 & $85-108$ & & 93 \\
\hline 10 & Tiler & 344 & 91 & $87-91$ & & 91 \\
\hline 11 & Crane operator & 323 & 92 & $79-98$ & & 92 \\
\hline 12 & Driver/chauffeur & 283 & 91 & & & 91 \\
\hline 13 & Mechanical woodworker & 282 & 93 & $83-96$ & $87-95$ & 91 \\
\hline 14 & Concrete bender & 237 & 89 & $82-89$ & & 89 \\
\hline 15 & Concrete scraper & 224 & 91 & $87-92$ & & 91 \\
\hline 16 & Mechanic (machines) & 214 & 92 & $90-95$ & & 92 \\
\hline 17 & Pipelayer & 200 & 91 & $85-95$ & & 91 \\
\hline 18 & Mechanic & 192 & 92 & $82-96$ & & 92 \\
\hline 19 & Pile driver & 145 & 96 & & 80-103 & 86 \\
\hline 20 & Destructor & 140 & 89 & & 81-109 & 96 \\
\hline
\end{tabular}

variable. The possible statistically significant interaction of noise intensity and noise exposure time is tested by adding a product term in regression analyses.

In addition, multiple linear regression analysis is used for the analysis of combined action of different parameters on PTA $_{3,4,6}$ values. Modelling proceeded in several steps. First, bivariate relationships of the covariates with PTA $_{3,4,6}$ are checked by simple linear regression. All analyses are adjusted for age by including age as a covariate. Most of the categorical variables are dichotomous, and others are converted into dummy variables before inclusion into the analysis. Variables are retained for further modelling if the age-adjusted $p$ value of the individual testing was $<0.10$. Second, a multiple linear regression model is created using the selected set of potential predictive variables. Relevant variables are selected using a backward stepwise elimination procedure, with $p<0.05$ for inclusion and $p<0.10$ for exclusion.

The use of hearing protection devices reduces noise exposure, which may lead to overestimation of exposure levels and attenuation of the exposure-response relationship (Sbihi et al. 2010). To reduce the effects of hearing protection, some analyses are adjusted for reported HPD use by performing stratified analyses for the subgroups of HPD users and non-users.

The level for statistical significance is taken as $p<0.01$ for all analyses.

\section{Results}

General population characteristics

The total population of 27,644 men is divided into a large group of noise-exposed employees $(n=24,670)$ and an internal non-exposed control group $(n=1,016)$. The exposed group is slightly older than that of the control group (average age 44.3 and 40.9 years, respectively, see Table 2). Noise-exposed workers are significantly longer employed in both the construction industry and their current occupation than controls. Mean employment differences are 12.4 and 6.7 years, respectively. More than half of the exposed workers have always been employed in the current job (55.5\%). Of the exposed employees, $75.5 \%$ claim to use hearing protection, $22.1 \%$ have complaints of worsened hearing and $39.1 \%$ are bothered by noise during work. Smoking status, alcohol intake and blood pressure do not differ between the groups.

Hearing threshold levels

To examine the hearing ability of the employees, median hearing threshold levels of the noise-exposed workers are compared to median HTLs of the non-exposed controls and to age-matched thresholds reported in annex A of the ISO1999 standard (Fig. 1). 
Table 2 Demographics and hearing loss risk factors, by subject group

* Difference between groups is significant at 0.01 level

Italic values represent

percentages

\begin{tabular}{lll}
\hline Variables & Exposed & Controls \\
\hline$n$ & 24,670 & 1,016 \\
Age, yrs (mean \pm SD)* & $44.3 \pm 11.4$ & $40.9 \pm 11.5$ \\
Years in construction (mean \pm SD)* & $24.3 \pm 12.6$ & $11.9 \pm 10.2$ \\
Years in current job (mean \pm SD)* & $18.6 \pm 12.8$ & - \\
Always employed in current job (\%)* & 55.5 & 9.9 \\
Usage of HPD (\%)* & 75.3 & 11.7 \\
Complaints of worsened hearing (\%)* & 22.1 & 4.5 \\
Bothered by noise during work (\%)* & 39.1 & 36.4 \\
Smoking & & 33.5 \\
Never (\%) & 35.0 & 30.1 \\
Current (\%) & 32.8 & $14.2 \pm 9.2$ \\
Ex (\%) & 32.2 & $18.9 \pm 11.7$ \\
Cigarettes/day (mean \pm SD) & $14.7 \pm 9.9$ & $9.8 \pm 10.3$ \\
Years of smoking (mean \pm SD) & $18.9 \pm 11.8$ & 19.7 \\
Alcohol intake, glasses/week (mean \pm SD) & $9.8 \pm 10.3$ & \\
Hypertension (\%) & 21.6 & - \\
L Aeq, 8h (dBA) & & - \\
$80-84(\%)$ & 0.6 & - \\
$85-89(\%)$ & 29.0 & \\
$90-94(\%)$ & 68.7 & \\
$>95(\%)$ & 1.7 & \\
\hline
\end{tabular}

Both noise parameters and the interaction term show a significant bivariate association with the PTA-values. However, the interaction term does not contribute significantly to both multivariate regression models and is excluded from further analyses. For PTA $_{1,2,4}$, the model accounts for $24.3 \%$ of the variance. The age-adjusted regression coefficient for noise level is 0.14 (99\% CI $0.11-0.19)$, for years of exposure this is 0.07 (99\% CI 0.05-0.09). The regression model for $\mathrm{PTA}_{3,4,6}$ accounts for $32.4 \%$ of the variance. Also the age-adjusted regression coefficients for noise level and exposure time are higher for $\mathrm{PTA}_{3,4,6}, 0.27(99 \% \mathrm{CI} \quad 0.22-0.32)$ and 0.12 (99\% CI 0.09-0.15), respectively.

To gain more insight into the relationship between hearing loss and noise exposure, the impact of both parameters on hearing loss is further explored in separate analyses. The age-corrected hearing thresholds enable comparison to the noise-induced permanent threshold shift (NIPTS) predicted by ISO-1999. These NIPTS values are functions of audiometric frequency, exposure level and exposure time. For each individual construction worker, his expected median NIPTS is computed.

PTA $_{3,4,6}$ is most affected by noise, and this age-corrected pure-tone average is examined as function of exposure duration. For exposure times between 10 and 40 years, the median value of expected NIPTS and its distribution can be calculated. For exposure times shorter than 10 years, median expected NIPTS values are 

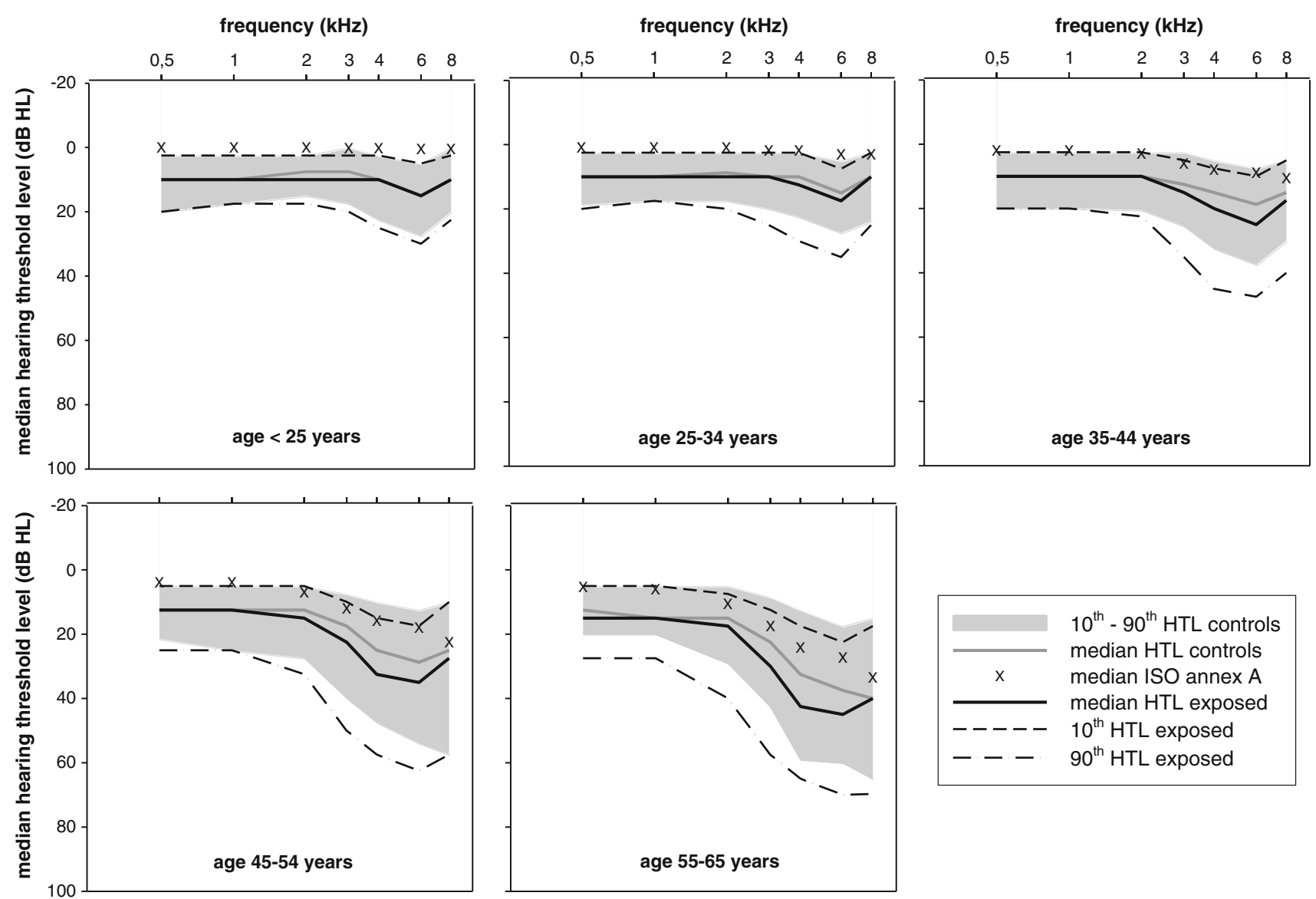

Fig. 1 Measured hearing thresholds levels of the exposed workers (thick black lines), compared to the non-exposed internal controls (grey area) and age-matched ISO predictions of annex A (crosses), for five age groups

interpolated from the value of NIPTS for 10 years, according to ISO-1999 (Fig. 2).

Although the inter-individual variation in the age-corrected hearing thresholds is larger in the exposed construction workers than predicted by ISO-1999, the median values of both groups follow a similar pattern for exposure times ranging from 10 to 40 years. However, this is not the case in the first 10 years of exposure. Where median values of ISO are interpolated to a NIPTS of $0 \mathrm{~dB}$ HL at the start of noise exposure, the population of noise-exposed construction workers shows age-corrected $\mathrm{PTA}_{3,4,6}$ values that are approximately $10 \mathrm{~dB}$ higher at the beginning of occupational noise exposure without the steep increase as is predicted by ISO-1999.

Similarly, age-corrected $\mathrm{PTA}_{3,4,6}$ values as function of daily noise exposure level are examined (Fig. 3).The nonexposed control group accounted for the starting point at $80 \mathrm{~dB}(\mathrm{~A})$. There are large differences in the distributions of age-corrected hearing thresholds between the exposed study group and the ISO-1999 reference population. Hearing loss variation is, again, much greater in exposed employees, and their $\mathrm{PTA}_{3,4,6}$ values are almost evenly distributed over the range of noise intensities. Hearing loss increases only slightly with increasing noise exposure level in this population, resulting in an almost flat curve that deviates strongly from the NIPTS predicted by ISO-1999. Up to exposure levels of $91 \mathrm{~dB}(\mathrm{~A})$, construction workers exhibit a greater hearing loss than predicted, while at higher noise levels less hearing loss is observed.

\section{Other variables of influence}

Data collection during periodic occupational health examinations also provides information about various factors possibly associated with NIHL, such as, the use of hearing protection, smoking and hypertension. To investigate the association between these risk factors and hearing loss, bivariate and multivariate regression analyses are performed. These analyses focus on PTA $_{3,4,6}$ only and are adjusted for the confounding effect of age. Results are displayed for the overall population and for both HPD subgroups separately in Table 3. 


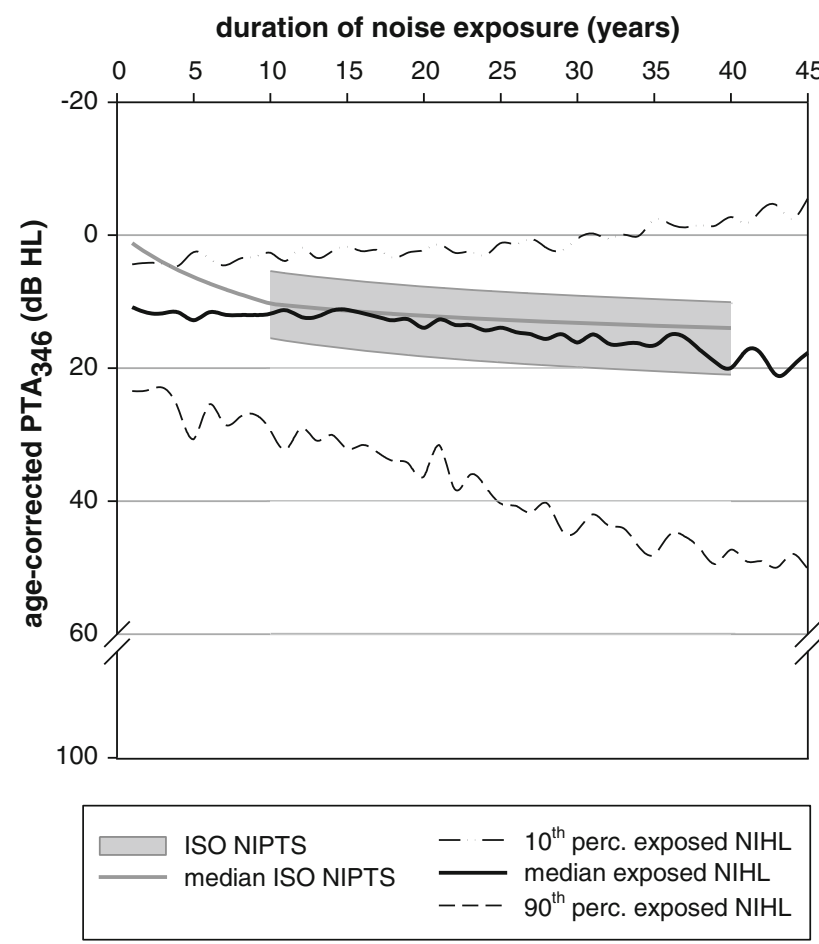

Fig. 2 Median, 10th and 90th percentile age-corrected $\mathrm{PTA}_{3,4,6}$ values of exposed population (black lines) and NIPTS distribution calculated using ISO-1999 (grey area) as a function of exposure time

Age, noise intensity and exposure time have shown to be significant contributors to the regression model. The addition of other potential risk factors improves the model fit statistic from 32.6 to $42.0 \%$.

For the overall population, the additional variables that remain significant in the multivariate model include the use of hearing protection, no change in job history, noise nuisance at work and the presence of hearing complaints.
The use of hearing protection shows a positive association with PTA $_{3,4,6}$ values, meaning that employees using hearing protection exhibit slightly more hearing loss than participants never using HPDs. Always being employed in the current job is associated with significantly greater hearing loss, and there is a strong correlation between the subjective complaints about poor hearing and the degree of hearing loss.

\section{Hearing protection}

Only $77 \%$ of the employees exposed to daily noise levels exceeding $80 \mathrm{~dB}(\mathrm{~A})$ report to wear hearing protection devices at work, meaning that $23 \%$ of the exposed workers state to never use protection.

Regression analyses show that employees using HPDs have an overall increase in PTA $_{3,4,6}$ of on average $1.4 \mathrm{~dB}$ with regard to employees never using protection, after adjusting for relevant covariates. To gain more insight into the differences between participants using hearing protectors and participants not using protection, both groups are analysed separately.

These analyses show that HPD users are employed in construction for a slightly shorter period ( 24.0 vs. 25.4 years) and are significantly younger than non-users (43.7 and 46.1 years, respectively). The percentage of HPD users declines with increasing age from $83.2 \%$ in employees younger than 25 years to $68.5 \%$ of the workers 55 years or older. Of the HPD users $44.8 \%$ indicated to be bothered by noise in their jobs, which is twice as much as the $21.6 \%$ in the non-user group. More importantly, the intensity of noise exposure differs significantly between HPD users and HPD non-users (90.6 and $89.5 \mathrm{~dB}(\mathrm{~A})$, respectively).
Fig. 3 Median, 10th and 90th percentile age-corrected PTA $_{3,4,6}$ values of exposed population (black lines) and NIPTS distribution calculated using ISO-1999 (grey area), as a function of daily noise exposure level. Left NIHL in HPD non-users. Right NIHL in HPD users

\section{HPD non-users}

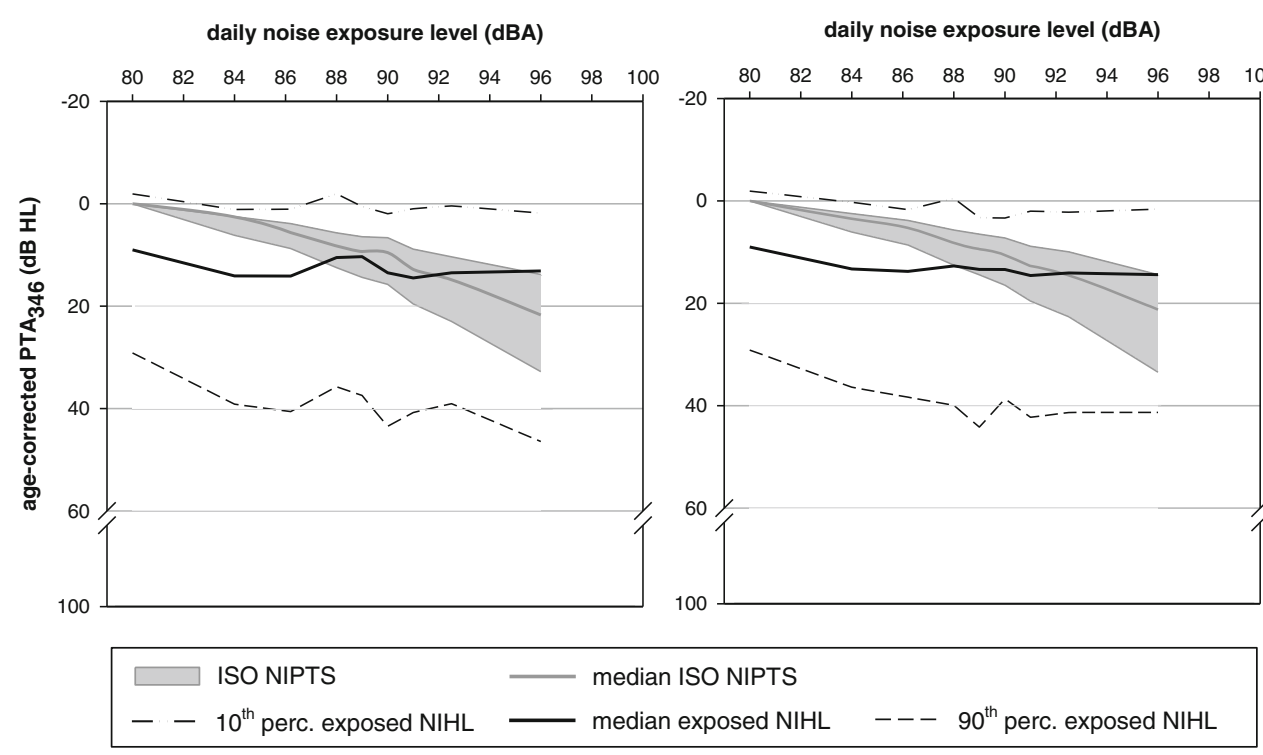




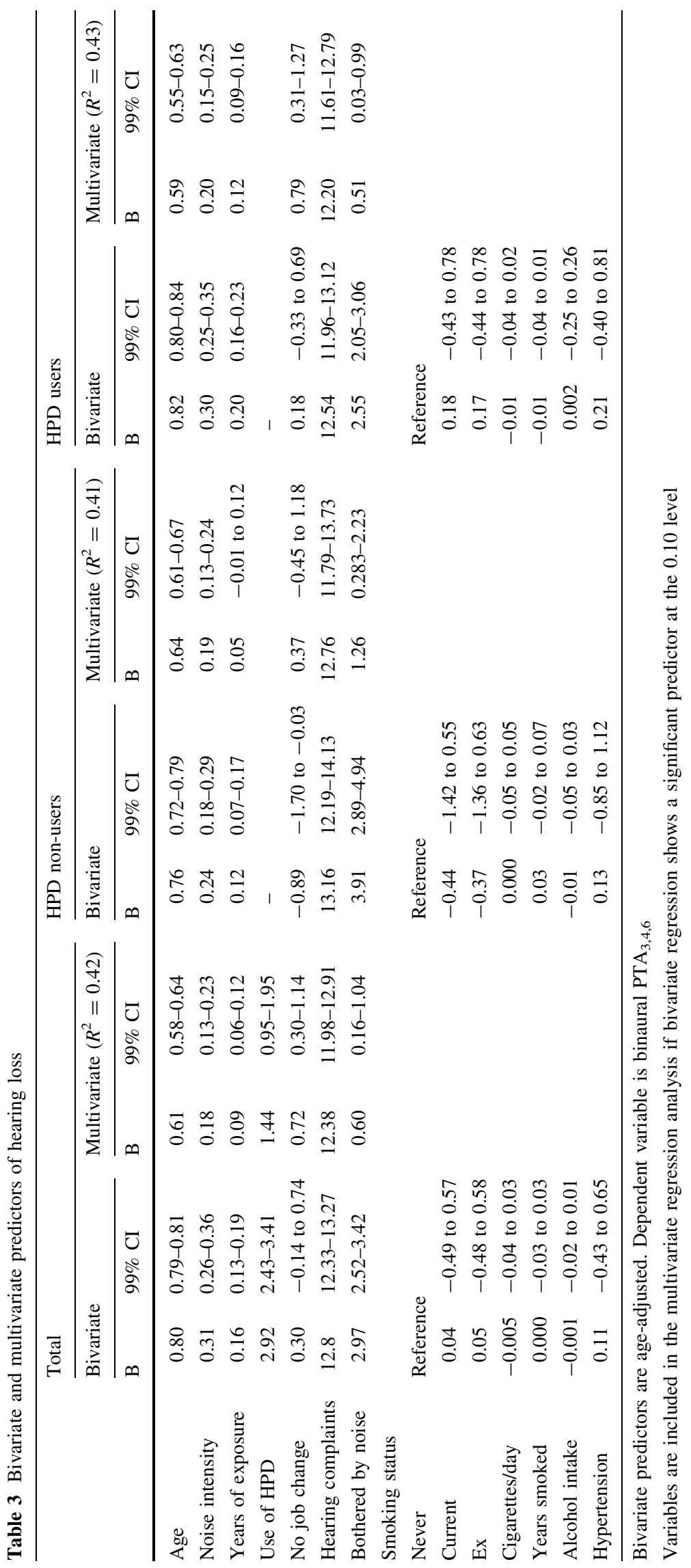


Stratified regression analyses for the subgroups of HPD users and HPD non-users did not show any differences between the results of both subgroups and of the overall population, except for the insignificant contribution of job history to the model for the non-users (Table 3). However, the regression coefficient found for noise intensity in the non-user group was slightly higher than in the user group. Nevertheless, Fig. 3 does not show a stronger relationship of noise exposure level with age-corrected PTA $_{3,4,6}$ values in the non-user group compared to HPD users.

When dividing the noise exposure levels into high noise intensities (>90 dB(A)) and moderate noise levels (between 80 and $90 \mathrm{~dB}(\mathrm{~A})$ ), it is shown that $84.4 \%$ of the highly exposed workers report to use HPDs versus $53.6 \%$ of the employees exposed to moderate noise levels. A stratified regression analysis for these two groups showed that HPD use only showed significant association with PTA $_{3,4,6}$ in workers exposed to noise levels between 80 and $90 \mathrm{~dB}(\mathrm{~A})$ (data not shown).

\section{Discussion}

The results of this study confirm the adverse effect of noise exposure on hearing threshold levels; the construction workers exposed to noise have poorer hearing thresholds compared to their non-exposed colleagues and to an international reference population, especially in the $3-6 \mathrm{kHz}$ region.

\section{Audiometric results}

This study shows a maximum mean deviation of $16.5 \mathrm{~dB}$ at $6 \mathrm{kHz}$ from the ISO reference population. Compared to the internal control group, the greatest average difference is $7.0 \mathrm{~dB}$, at $4 \mathrm{kHz}$.

Although these differences are not as large as expected, the findings are in agreement with a study of Suter (2002). That study reports hearing threshold levels of carpenters and equipment operators that were approximately $5 \mathrm{~dB}$ worse than the HTLs reported in annex B of ISO-1999 in the high frequency region. The unscreened reference population of annex B reports HTLs, which are comparable to the high frequency thresholds measured in our internal control group.

Nevertheless, the small group effects do not rule out significant threshold shifts in the ears of individuals that are more susceptible to noise-induced hearing loss than on average.

\section{Study limitations}

Although the main strength of this study was the size of the study population showing only a small percentage of missing values, some limitations in test administration and data collection cannot be avoided.

When comparing hearing threshold levels of construction workers to ISO-1999 standard values, both noiseexposed workers and controls show a deviation of about $10 \mathrm{~dB} \mathrm{HL}$ at the lower frequencies. This deviation is reported in other studies as well, either in control groups used to analyse hearing ability of construction employees (Hessel 2000; Hong 2005) or in a general occupational population (Dobie 2007). In this study, some aspects of test administration may have been responsible for this difference.

The available audiometric data are retrieved from screening assessments, omitting measurements of bone conduction. Therefore, we cannot correct for the presence of possible conductive hearing losses (e.g. due to permanent middle ear problems or temporarily conductive losses caused by a cold) that may be responsible for the elevated thresholds at the lower frequencies. Moreover, audiometric measurements are carried out on location in a mobile unit equipped with a soundproof booth. Nevertheless, possible exposure to background noise during the hearing test, which could produce elevated thresholds at $0.5 \mathrm{kHz}$, and to a lesser extent at $1 \mathrm{kHz}$ (Suter 2002), cannot be ruled out completely.

Furthermore, in this study no fixed noise-free period prior to audiometric measurements is defined. However, minimal time between possible occupational noise exposure and hearing tests was 2-3 h. Guidelines in literature recommend a longer noise-free period, varying from 6 to 14 h (NCvB 1999; May 2000). Consequently, the noisefree period of 2-3 h may not be sufficient to fully recover from a possible temporary threshold shift (TTS) (Melnick 1991; Strasser et al. 2003), and a complete absence of TTS cannot be guaranteed.

Moreover, collecting the appropriate data for noise exposure in this large population appears to be another limitation in this study. This study lacks individually measured noise exposure levels. Because construction workers are highly mobile and perform several different tasks, it is extremely difficult to obtain accurate estimates of the individual noise exposure levels.

Noise exposure estimations

Although regression analyses confirm a significant relationship between noise intensity and PTA-values, the hearing thresholds increase only marginal with increasing noise exposure level. This relationship follows a much flatter curve than predicted by ISO-1999.

A previous examination of Dutch industry workers compared single frequency threshold levels to ISO predictions (Passchier-Vermeer 1986) and obtained a similar 
pattern, suggesting that ISO underestimates hearing loss at lower exposure levels and overestimates hearing loss at higher noise levels. In a more recent study, the shift between baseline and follow-up audiograms showed good agreement with model predictions (ANSI 3.44 1996) at lower noise exposure levels, while at higher noise intensities less hearing loss than predicted was observed (Rabinowitz et al. 2007).

In the current study, individual noise exposure intensities are assigned based on job titles. This may have been too simplistic. It does not take into account that exposure may vary extensively between workers and over time. The diversity in specific tasks and the variety of equipment used at different workplaces introduces uncertainty in the calculations of noise exposure (Passchier-Vermeer 1986; Rabinowitz et al. 2007). As a consequence, the resulting estimates are not accurate enough to obtain a reliable doseeffect relationship.

Although the majority of the noise level estimates used in this study are mainly based upon carefully conducted sound level measurements and/or on personal dosimetry, noise levels are determined during a limited period of time. Therefore, the noise estimations are only samples and this limited sampling in complex and variable job situations, may have resulted in less accurate estimations.

Finally, the present noise exposure levels are also used as estimations of past exposure. Noise exposure levels of the construction workers may have varied considerably over their career. Regression analyses show only a small effect of prior employment on hearing, but the changes within jobs overtime may have limited the validity of the noise intensity estimations.

All these uncertainties in noise level estimations may have obscured a clear dose-effect relationship for the individual construction worker. However, for groups of workers with a sufficient number of employees, we may assume that most of the uncertainties mentioned above, e.g. the day-to-day variability and variations between individual workers, will be averaged out. Although the relations found in such an approach may be prone to some bias, we did not expect to find such a weak dose-effect relationship.

Attenuation of noise exposure from the use of hearing protection might partly explain the lack of the typical dose-response effect between noise level and hearing loss as well (Rabinowitz et al. 2007). The use of HPDs can cause inaccuracy in individual noise exposure estimation. This may have resulted in an overestimation of hearing loss for HPD users at noise intensities exceeding $90 \mathrm{~dB}(\mathrm{~A})$, at which a higher percentage of usage is reported. For this reason, stratified analysis for subgroups of HPD users are performed. The interpretation the results of the HPD users is difficult because data on the effectiveness of hearing protection and the consistency of wearing are unknown.
But also for the non-users the results do not show the expected relationship of noise intensity and hearing loss (Fig. 3).

Apparently, the variability between individual workers combined with confounding factors such as the use of hearing protection, differences in past exposure, slight TTS-effects, and the inaccuracy of the noise exposure estimations prevent us from making accurate predictions of the effects of noise intensity on hearing, even in a population of this large size.

\section{Effects of hearing protection}

Hearing protection may have its greatest effect at high ambient noise levels. Workers exposed to higher noise intensities are obliged to wear hearing protection and are more bothered by ambient noise, making them more consistent in wearing their protection (Rabinowitz et al. 2007). In lower ambient noise levels HPDs may interfere with communication, jeopardizing the consistency of usage (Suter 2002). Current analysis shows that $84.4 \%$ of the employees exposed to noise levels exceeding $90 \mathrm{~dB}(\mathrm{~A})$ indicated to use HPDs versus $53.6 \%$ of the employees exposed to noise levels between 80 and $90 \mathrm{~dB}(\mathrm{~A})$.

Regression analysis shows a positive association of hearing loss and HPD use; employees using HPDs had on average $1.4 \mathrm{~dB}$ higher $\mathrm{PTA}_{3,4,6}$ values than non-users. Bauer et al. (1991) also found a positive association between of the usage of HPDs and hearing loss by analysing a very large population of workers exposed to occupational noise. This can be explained by the suggestion that workers with beginning hearing problems are better motivated to use HPDs more consistently than their colleagues without hearing problems.

When workers are divided into highly exposed employees and employees exposed to moderate noise levels (80-90 dB(A)), HPD usage only shows a significant association with hearing in the moderately exposed group (data not shown). HPD use does not contribute significantly to the multivariate regression model for $\mathrm{PTA}_{3,4,6}$ in the highly exposed group, despite the assumption that these are more consistent users.

In this study, HPD usage was scored as a binary variable, while the actual consistency of usage would be a more suitable predictor. The individual fitting of HPDs, the consistency of HPD usage and exposure level during use and non-use are crucial elements in determining the actual noise dose (Seixas et al. 2005).

In addition, HPD data are based on employees' selfreport, which can be subject to reporting bias and social desirability (Griffin et al. 2009). These uncertainties can lead to misclassification, thereby overestimating HPD 
usage and underestimating the true effect of hearing protection (Davies et al. 2008).

Unfortunately, data about the effectiveness of the HPDs and about the consistency of usage were unavailable.

\section{Effects of noise exposure time}

The relationship of hearing loss and exposure time, defined as years of employment in construction, is also explored. Exposure time is positively related to hearing threshold levels; longer exposure times are associated with higher PTA $_{3,4,6}$ values.

This effect was about $0.09 \mathrm{~dB}$ loss in PTA $_{3,4,6}$ for each year of exposure, after adjustment for age, noise intensity, and other risk factors. This increase is similar as reported in ISO-1999, which predicts an average increase in median PTA $_{3,4,6}$ values of $1 \mathrm{~dB} /$ decade for exposure levels of $90 \mathrm{~dB}$ (A) (ISO 1990). Also a review by Rösler (1994) reports the same amount of increase in age-corrected HTLs at $4 \mathrm{kHz}$, after the first 10 years of exposure.

When comparing the age-corrected $\mathrm{PTA}_{3,4,6}$ values of the study population and the ISO predicted NIPTS as a function of exposure time, the greater inter-individual variation in the distribution of NIHL in exposed construction workers is remarkable. This suggests a high variation in factors influencing the susceptibility to hearing loss in each exposure year interval of the study group, such as HPD use, prior employment, non-occupational noise exposure, hearing disorders, and variability in noise intensity.

However, the median values of both the noise-exposed workers and the ISO predictions have a similar slope, at least for exposure times between 10 and 40 years.

An interesting aspect is the relationship during the first 10 years of noise exposure. Construction workers employed for less than 10 years show greater hearing losses than expected based on the interpolation of ISO1999. In addition, observed hearing loss increases over the first 10 years of exposure at the same rate as in the following 10-40 years of exposure duration, where a pattern of strongly increasing thresholds would have been expected (ISO 1990; Rösler 1994; Prince 2002).

To investigate the role of job history in this group with short exposure duration, this relationship is determined only for construction workers younger than 30 years of age that reported no prior employment. This selection of 2,190 employees shows the same pattern of median age-corrected PTA $_{3,4,6}$ values that is about $10 \mathrm{~dB}$ higher than predicted by ISO.

A number of previous studies also found a discrepancy between ISO predictions and measured hearing loss during the first years of exposure. Analyses based on serial audiograms of railway workers showed that hearing thresholds exceed model predictions in the very beginning of noise exposure, showing age-corrected hearing loss at job entrance of $9 \mathrm{~dB}$ averaged over 2 and $4 \mathrm{kHz}$ (Henderson and Saunders 1998). Another study, monitoring a cohort of newly enrolled construction apprentices, showed HTLs of $12.2 \mathrm{~dB} \mathrm{HL}$ at $4 \mathrm{kHz}$ at baseline (Seixas et al. 2004) without any change in audiometric hearing thresholds over the first 3 years of employment (Seixas et al. 2005). The reported hearing threshold levels at job entrance in these studies are all higher than $0 \mathrm{~dB}$ HL and correspond to the median age-corrected PTA $\mathrm{P}_{3,4,6}$ of $10.9 \mathrm{~dB} \mathrm{HL}$ found here.

The ISO-1999 model depends on the interpolation of predicted hearing thresholds after 10 years of exposure and the assumed hearing thresholds of $0 \mathrm{~dB} \mathrm{HL}$ at the beginning of employment. Our findings suggest that this may not correctly represent the true development of NIHL over this period of exposure. The interpolation of the ISO formula could either be less applicable to the population of interest, or the starting point of $0 \mathrm{~dB}$ HL is set too low, possibly due to the fact that the amount of early hearing damage in this population is underestimated.

NIHL in young employees

A Dutch survey of health-related and occupational problems among construction workers shows that $7.6 \%$ of construction workers younger than 25 years are diagnosed with NIHL (Arbouw 2009). Reported prevalence of hearing loss among young adults entering the construction industry in literature is even higher, ranging from 14.4 to 16\% (Rabinowitz et al. 2006; Seixas 2005). This suggests that the starting point of $0 \mathrm{~dB}$ HL defined in ISO-1999 is set too low in this population, because NIHL is already present in workers even before employment. Possibly, this is caused by noise exposure in recreational settings, underlining that non-occupational noise is another complicating factor in the relationship of occupational noise exposure and hearing impairment. Neitzel et al. (2004) demonstrated that approximately one-third of apprentices in the construction industry experience equivalent noise levels higher than $80 \mathrm{~dB}(\mathrm{~A})$ from recreational noise exposure, placing them at risk for NIHL even before considering occupational exposure. Effects of both occupational and non-occupational noise exposure will accumulate and exposure to non-occupational noise prevents workers to recover from occupational noise exposure. Since the current study was conducted during audiometric screening in an occupational health setting, no information concerning exposure to leisure noise is available. Information about non-occupational noise exposure and a baseline audiometric measurement would be highly advisable for medico-legal purposes. 
Effects of confounding factors

The influence of other possible confounding factors must be considered when interpreting the presented relationships between hearing loss and noise exposure. Despite confounding factors such as job history and use of hearing protection, the multiple linear regression analysis still show a significant contribution of noise exposure to the regression model. Lifestyle factors, such as smoking, alcohol intake and hypertension, do not show a relationship with NIHL in this population. The multivariate model for PTA $_{3,4,6}$ only explains $41.1 \%$ of the variance in hearing threshold levels; hence, most of the variation is not explained by variables measured in this study. Other studies performing multiple regression analyses to examine the effect of noise exposure and hearing ability adjusted for several confounders, found smaller $R^{2}$ for their multivariate models of 30.6\% (Agrawal et al. 2010) and 36\% (Toppila et al. 2000).

Differences in the individual susceptibility to noise may be responsible for the large spread of individual threshold values. Several possible explanatory variables that hypothetically could be responsible for part of the variance, such as medical history, non-occupational noise exposure and drug usage, are not included in these analyses, because of a lack of information concerning these factors.

\section{Conclusion}

This analysis of a large audiometric dataset show that Dutch construction workers exhibit greater hearing losses than expected based solely on ageing. Accumulation of the inevitable age-related hearing loss may result in moderate to severe hearing impairment at retirement age.

Regression models show a great inter-individual variability in reported hearing loss, and only a weak relationship between noise level and hearing ability is found. At low noise exposure levels, hearing loss is much greater than predicted whereas at high levels hearing loss is less. This latter might be partly explained by the role of personal hearing protection, which is worn by a greater proportion of highly exposed workers than workers exposed to lower noise levels. Individual noise exposure level measurements can increase the accuracy of the noise intensity estimates and results in a more reliable estimate of this relationship.

Growth of hearing loss with progressing exposure time is in accordance with ISO predictions for exposure durations between 10 and 40 years. However, the interpolation described in the ISO model that predicts hearing loss developed during the first 10 years of exposure is not consistent with our data and seems to be inapplicable in this population. Our hypothesis is that pre-existing hearing loss from non-occupational noise exposure is the most important explanation for this inconsistency.

In a follow-up study, personal dosimetry and extensive information on job history should be taken into account estimating noise exposure levels. In addition, serial audiometry with a baseline measurement at job entrance should be performed and more detailed information should be collected about factors influencing hearing ability, such as, non-occupational noise exposure, medical history and details of hearing protector usage.

Acknowledgments The authors acknowledge Arbouw for the collection and management of all occupational health-related data. Special thanks to Hiske Helleman and Noortje Jansen for their assistance with data analysis. This research was funded by Arbouw.

Conflict of interest The authors declare that they have no conflict of interest.

Open Access This article is distributed under the terms of the Creative Commons Attribution Noncommercial License which permits any noncommercial use, distribution, and reproduction in any medium, provided the original author(s) and source are credited.

\section{References}

Agrawal Y, Niparko JK, Dobie RA (2010) Estimating the effect of occupational noise exposure on hearing thresholds: the importance of adjusting for confounding variables. Ear Hear 311:234-237

ANSI S 3.44 (1996) Determination of occupational noise exposure and estimation of noise-induced hearing impairment. American National Standards Institute, New York

Arbouw (2009) Bedrijfstakatlas 2009. Stichting Arbouw, Harderwijk

Arndt V, Rothenbacher D, Brenner H, Fraisse E, Zschenderlein B, Daniel U, Schuberth S, Fliedner TM (1996) Older workers in the construction industry: results of a routine health examination and a five year follow up. Occup Environ Med 53:686-691

Bauer P, Körpert K, Neuberger M, Raber A, Schwertz F (1991) Risk factors for hearing loss at different frequencies in a population of 47.388 noise-exposed workers. J Acoust Soc Am 90:3086-3098

Davies H, Marion S, Teschke K (2008) The impact of hearing conservation programs on incidence of noise-induced hearing loss in Canadian workers. Am J In Med 51:923-931

Dawson-Saunders B, Trapp RG (1994) Basic and clinical biostatistics, 2nd edn. Appleton Lange, Connecticut

De Moraes Marchiori LL, de Almeida Rego FE, Matsuo T (2006) Hypertension as a factor associated with hearing loss. Bras J Otorhinolaringol 72:533-540

Dobie RA (2006) Methodological issues when comparing hearing thresholds of a group with population standards: the case of the ferry engineers. Ear Hear 27:526-537

Dobie RA (2007) Noise-induced permanent threshold shifts in the occupational noise and hearing survey: an explanation for elevated risk estimates. Ear Hear 28:580-591

Dobie RA (2008) The burdens of age-related and occupational noiseinduced hearing loss in the United States. Ear Hear 29:565-577

Edelson J, Neitzel R, Meischke H, Daniell W, Sheppard L, Stover B, Seixas N (2009) Predictors of hearing protection use in construction workers. Ann Occup Hyg 53:605-615 
Griffin SC, Neitzel R, Daniell WE, Seixas NS (2009) Indicators of hearing protection use: self-report and researcher observation. J Occup Environ Hyg 6:639-647

Henderson D, Saunders SS (1998) Acquisition of noise-induced hearing loss by railway workers. Ear Hear 19:120-130

Henderson D, Subramaniam M, Boettcher FA (1993) Individual susceptibility to noise-induced hearing loss: an old topic revisited. Ear Hear 14:152-168

Hessel PA (2000) Hearing loss among construction workers in Edmonton, Alberta, Canada. J Occup Environ Med 42:57-63

Hong O (2005) Hearing loss among operating engineers in American construction industry. Int Arch Occup Environ Health 78:565574

ISO 6189 (1983) Acoustics-pure tone air conduction threshold audiometry for hearing conservation purposes, 1st edn. International Organisation for Standardization, Geneva

ISO 389 (1991) Acoustics-reference zero for the calibration of audiometric equipment, 3rd edn. International Organisation for Standardization, Geneva

ISO 1999 (1990) Acoustics - determination of occupational noise exposure and estimation of noise-induced hearing impairment, 2nd edn. International Organisation for Standardization, Geneva

Kurmis AP, Apps SA (2007) Occupationally-acquired noise-induced hearing loss: a senseless workplace hazard. Int J Occup Med Environ Health 20:127-136

Lusk SL, Kerr MJ, Kauffman SA (1998) Use of hearing protection and perceptions of noise exposure and hearing loss among construction workers. Am Ind Hyg Assoc J 59:466-470

May JJ (2000) Occupational hearing loss. Am J Ind Med 37:112-120

Melnick W (1991) Human temporary threshold shift (TTS) and damage risk. J Acoust Soc Am 90:147-154

Mizoue T, Miyamoto T, Shimizu T (2003) Combined effect of smoking and occupational exposure to noise on hearing loss in steel factory workers. Occup Environ Med 60:56-59

NCvB (1999) Registratierichtlijn B001. Beroepslechthorendheid 503: hardhorendheid of doofheid ten gevolge van lawaai. Nederlands Centrum voor Beroepsziekten, Amsterdam

NCvB (2009) Beroepsziekten in cijfers 2009. Nederlands Centrum voor Beroepsziekten, Amsterdam

Neitzel R, Seixas N (2005) The effectiveness of hearing protection among construction workers. J Occup Environ Hyg 2:227-238

Neitzel R, Seixas N, Goldman B, Daniell W (2004) Contributions of non-occupational activities to total noise exposure of construction workers. Ann Occup Hyg 48:463-473

Passchier-Vermeer W (1986) The effects of age, otological factors and occupational noise exposure on hearing threshold levels of various populations. In: Salvi RJ, Henderson D, Hamernik P, Coletti V (eds) Basic and applied aspects of noise-induced hearing loss. Plenum Press, New York, pp 571-581

Passchier-Vermeer W, Hof W van, Rovekamp AJM (1991) Het gehoor van werknemers in de bouwnijverheid. Instituut voor preventieve gezondheidszorg. TNO, Leiden
Prince MM (2002) Distribution of risk factors for hearing loss: implications for evaluating risk of occupational noise-induced hearing loss. J Acoust Soc Am 112:557-567

Prince MM, Gilbert SJ, Smith RJ, Stayner LT (2003) Evaluation of the risk of noise-induced hearing loss among unscreened male industrial workers. J Acoust Soc Am 113:871-880

Rabinowitz PM, Slade MD, Galusha D, Dixon-Ernst C, Cullen MR (2006) Trends in the prevalence of hearing loss among young adults entering an industrial workforce 1985-2004. Ear Hear 27:369-375

Rabinowitz PM, Galusha D, Dixon-Ernst C et al (2007) Do ambient noise exposure levels predict hearing loss in a modern industrial cohort? Occup Environ Med 64:53-59

Rösler G (1994) Progression of hearing loss caused by occupational noise. Scand Audiol 23:13-37

Sbihi H, Teschke K, MacNab YC, Davies HW (2010) An investigation of the adjustment of retrospective noise exposure for use of hearing protection devices. Ann Occup Hyg 54:329-339

Seixas NS, Kujawa SG, Norton S, Sheppard L, Neitzel R, Slee A (2004) Predictors of hearing threshold levels and distortion product otoacoustic emissions among noise exposed young adults. Occup Environ Med 61:899-907

Seixas NS, Goldman B, Sheppard L, Neitzel R, Norton S, Kujawa SG (2005) Prospective noise induced changes to hearing among construction industry apprentices. Occup Environ Med 62:309317

Sliwińska-Kowalska M, Dudarewicz A, Kotyło P, ZamysłowskaSzmytke E, Pawlaczyk-łuszczyńska M, Gajda-Szadkowska A (2006) Individual susceptibility to noise-induced hearing loss: choosing an optimal method of retrospective classification of workers into noise-susceptible and noise-resistant groups. Int J Occup Med Environ Health 19:235-245

Strasser H, Irle H, Legler R (2003) Temporary hearing threshold shifts and restitution after energy-equivalent exposures to industrial noise and classical music. Noise Health 5:75-84

Suter AH (2002) Construction noise: exposure, effects, and the potential for remediation; a review and analysis. AIHA J (Fairfax, Va) 63:768-789

Tak S, Calvert G (2008) Hearing difficulty attributable to employment by industry and occupation: an analysis of the National Health Interview Survey-United States, 1997 to 2003. J Occup Environ Med 50:46-56

Taylor W, Pearson J, Mair A, Burns W (1965) Study of noise and hearing in jute weaving. J Acoust Soc Am 38:113-120

Toppila E, Pyykko I, Starck J, Kaksonen R, Ishizaki H (2000) Individual risk factors in the development of noise-induced hearing loss. Noise Health 2:59-70

Tufts JB, Weathersby PK, Marshall L (2009) Estimation of equivalent noise exposure level using hearing threshold levels of a population. Ear Hear 30:287-290

Wild DC, Brewster MJ, Banerjee AR (2005) Noise-induced hearing loss is exacerbated by long-term smoking. Clin Otolaryngol 30:517-520 